\title{
A RE-SIGNIFICAÇÃO DA FORMAÇÃO PERMANENTE, DA IDENTIDADE PRESBITERAL E DA IDENTIDADE DO PRESBÍTERO
}

Pe. João da Silva Mendonça Filho, sdb*

\begin{abstract}
RESUMO
$O$ autor mostra que a formação permanente não pode ser compreendida hoje senão a partir da re-significação da identidade presbiteral e da identidade do presbitero numa grande metamorfose social e, consequentemente, eclesial. Há não apenas o fato em si da formação permanente, mas o intertexto no qual ela se situa na mudança de época. O presbitero, consciente ou não, se redefine dentro da malha cultural. $O$ autor mostra também que desde o pós-Concílio Vaticano II os modelos de presbitero se redefinem, sobretudo no Brasil. No dinamismo destas mudanças, o imaginário coletivo, individual e as fiç̧ões que sempre caracterizam o ser humano mudaram, contribuindo também para novas interpretações da identidade, natureza e missão do presbítero católico. A formação
\end{abstract}

\begin{abstract}
The author shows that continuing education can not be understood today, but after re-signification of priestly identity and the identity of the priest in a large social metamorphosis, and consequently the Church. There is not only the fact itself of continuing education, but the intertext in which it lies in the change of season. The priest, consciously or not, is redefined within the cultural fabric. The author also shows that since the post-Vatican II council of elders models are redefined, especially in Brazil. Dynamism of these changes in the collective imagination, the individual and the fictions that had always characterized the human being changed, also contributing to new interpretations of the identity, nature and mission of a Catholic priest. Continuing Education, therefore, can not
\end{abstract}

\footnotetext{
É mestre em Educação com especialização em Pedagogia para a formação religiosa e presbiteral, pela Pontifícia Universidade Salesiana de Roma/Itália. Pós-graduado em Educação sexual pela UNISAL-SP e em Comunicação pelo SEPAC e PUC-SP.
} 
permanente, portanto, não pode ser delegada a ninguém; o presbítero é o primeiro protagonista do processo ao longo das idades da vida e de suas vivências espirituais e pastorais. $\mathrm{O}$ autor destaca também algumas perspectivas para o ministério presbiteral que devem ser assumidas neste grande processo de mudanças. Mudou o mito, o presbitero, mudaram as narrativas sobre o mito, e a arte e a literatura também sofreram transformações. Por conseguinte, faz-se urgente pensar o jeito de ser padre hoje com o custo de perder o rumo da história.

Palavras-chave: presbitero, presbiteral, formação permanente, metamorfose, re-significação. be delegated to any one; the priest is the first protagonist of the process along the stages of life and its spiritual and pastoral experiences. The author also points out some perspectives for the priestly ministry which must be assumed in this great process of change. Changed the myth, the priest, changed the narratives on the myth, and art and literature have also suffered changes. Therefore, it is urgent to think the way to be a priest today with the cost of losing the course of history.

Keywords: priest, priests, continuing education, metamorphosis, re-signification.

\section{QUESTÕES DE BASE DE UMA METAMORFOSE NA FORMAÇÃO}

Já estamos acostumados com a consagrada expressão do número 44 de Aparecida: "Vivemos uma mudança de época". O ENP' de 1987 já estava preocupado com estas mudanças. A questão era intuída como uma "nova colonização cultural pela imposição de culturas artificiais" (DA, 46), ${ }^{2}$ com a supervalorização do indivíduo, do estético, do consumo e dos direitos individuais e subjetivos (DA, 45-47). A pergunta, então é a seguinte: o que isto tem a ver com nossa identidade presbiteral e nossa identidade enquanto presbitero e com a formação permanente? Ressalvo que não é a mesma coisa dizer identidade presbiteral e identidade do presbítero. ${ }^{3}$ Aos poucos iremos destacando esta diferença.

1 A sigla ENP, daqui em diante, significa: Encontro Nacional de Presbiteros. Conferir bibliografia.

2 A sigla DA, daqui em diante, significa: Documento de Aparecida. Conferir bibliografia.

3 SANTOS, Pe. J. B. O presbítero Católico, uma identidade em transformação. Aparecida: Santuário, 2010, pp. 27-50. 
Para responder a esta pergunta precisamos saber ler o intertexto desta complexa malha cultural que envolve a identidade humana hoje. Se foi possível definir o ser humano como um animal racional até ontem, hoje nos perguntamos sobre o que é ser racional. Na linha do pensamento contemporâneo da subjetividade é possível imaginar um avatar, cuja conexão conosco nos mantém num contínuo processo de re-significação. Por conseguinte, o rosto presbiteral e 0 do presbítero se definem e se redefinem numa grande onda de desorganização da própria sociedade e da caminhada da Igreja pós-conciliar e seus desdobramentos na América Latina, sobretudo no Brasil. ${ }^{4}$

O que significa, portanto, saber aprender continuamente sem perder a essencialidade, não obstante as metamorfoses do tempo? É necessário pensar. "Uma Igreja que não pensa, diz o padre Zezinho, dá o que pensar". ${ }^{5}$ Parafraseando, ouso dizer: Um clero que não pensa dá o que falar. Dá para falar da mesmice que nos empobrece, da banalização do sagrado que nos seculariza das acrobacias litúrgicas que nos estressam, do autoritarismo que nos deixa sozinhos, da perda de credibilidade entre nós e do povo para conosco, do neoclericalismo como uma forma de autoafirmação etc. Trata-se de uma associação de mudanças oriundas das novas tecnologias, da globalização e da aceleração do tempo e da história. Também, é justo

4 No Brasil, os modelos de presbíteros podem ser assim definidos ao longo das décadas: 1. De 1960-1970: A partir do Vaticano II surgiu um padre despojado das vestes sagradas, das insígnias, dos privilégios e do poder sobre a sociedade. Foi a época da busca da identidade. O que dizes de ti mesmo? Padre, quem és? 2. De 1970 a 1980: A partir da concepção de uma Igreja toda ministerial e evangelizadora, o presbítero tornou-se o ministro da síntese como animador de carismas e ministérios, na linha da Lumen Gentium. A pergunta foi: Padre, o que fazes? Onde te colocas? 3. De 1980 a 1990: Surgiu o grande apelo à espiritualidade presbiteral. A pergunta fundamental era: Padre, como vives? O que te sustenta no teu ministério? 4. De 1990 a 2000: Com o reforço da Pastores Dabo Vobis o acento caiu sobre o sinal sacramento que o presbítero deveria ser - Cristo cabeça - Na eclesiologia da Igreja mistério, comunhão e missão a pergunta articulada era: Padre, qual é o sentido de tua vida e missão? De quem és sinal? 5 . De 2000 a 2009: Surgiram modelos de padres mais "light", preocupados com a realização pessoal e forte tendência tradicionalista com o retorno das insígnias, dos privilégios, de uma vivência mais espiritualizada e menos comprometida com as questões pastorais e sociais. A pergunta suscitada: Padre, com quem caminhas, com a Instituição ou com o povo? Evidentemente que para entender o desenvolvimento da identidade do presbítero no Brasil, sem cair em generalizações, é necessário recorrer aos 500 anos de historia do Brasil, mas este é um tema para outra conversa (Cf. SANTOS, Pe. J. B. O presbitero Católico, cit., pp. 150-152).

5 Pe. Zezinho. Por uma Igreja que pensa. In: Jornal O Lutador, junho-julho 2010. 
reconhecer que dá para falar do zelo apostólico de tantos irmãos presbíteros, da fidelidade ao ministério nas alegrias e tristezas, da capacidade de trabaIhar em equipe e com o protagonismo dos leigos, da ousadia profética de denunciar as ciladas do mau presente na sociedade e na Igreja, da crescente fraternidade presbiteral, do espírito missionário. Ressalto o pensamento do teólogo Paulo Sues sobre o padre elementar, exatamente na linha do que acabamos de dizer:

O padre elementar tem bom senso, prioriza as tarefas e elementiza a fé no meio das descrenças, diz com poucas palavras as razões de sua esperança, abraça o que o mundo considera descartável. Relaciona-se bem com as pessoas, com Deus e com a Igreja. ${ }^{6}$

O que, então, muda ou mudou e afeta a formação inicial e permanente? Cabe inclusive a pergunta feita numa pesquisa pedida pelos ENPs: Padre, você é feliz??

\section{OS ÂMBITOS DA METAMORFOSE DA FORMAÇÃO PERMANENTE}

Mudou o imaginário individual: quer dizer, a capacidade de sonhar e o cenário do sonho. Isto mudou. Em outras palavras: mudou o ser padre (identidade do presbítero) e deverá mudar pela força dos fatos a essencialidade do padre (identidade presbiteral). O discurso tradicional que lemos e ouvimos durante o Ano Sacerdotal não ecoou como se esperava, exatamente porque mudaram os paradigmas. Estamos de cheio na era pós-convencional e pós-metafísica. Perguntemos, então, sobre os modelos de padres. Quais são os modelos que impactam hoje? Qual é o sonho do seminarista e o cenário no qual ele sonha?

Mudou o imaginário coletivo: ou seja, a banalização do sagrado enquanto espaço de pessoas e objetos. ${ }^{8} \mathrm{O}$ mito está em crise; por conseguinte,

6 SUES, P. Memória, discernimento, compromisso: comunhão e missão presbiteral ontem e hoje. Palestra proferida no 13o. ENPs (3-4/02/2010) Itaici/SP, p. 27.

7 VALLE, E. (org.). Padre, você é feliz? Uma sondagem psicossocial sobre a realização pessoal dos presbiteros no Brasil. São Paulo: Loyola, 2004. Uma abordagem italiana realizada por uma socióloga no clero de Roma também detectou alguns elementos desta realidade psicossocial (cf. RUSSO, G. C. Essere sacerdote in un mondo che cambia. Milano: Italya, 1994).

8 LIBANIO, J. B. As lógicas da cidade, o impacto sobre a fé e sob o impacto da fé. São Paulo: Loyola, 2001, pp. 27ss. 
a natureza do mito também. Mircea Eliade diz que o "mito conta uma história", é sempre a narração de uma criação. ${ }^{9} \mathrm{~A}$ identidade presbiteral sofre uma recriação, consequentemente o ser presbítero necessariamente sofrerá um novo nascimento no coletivo. Este coletivo é tanto a sociedade como cenário do grande teatro da narração como também nossas pessoas enquanto personagens deste relato. Muda dentro de nós, dia a dia, a concepção de ser presbítero. É urgente, portanto, aprender a pensar num mundo complexo, quer dizer, "saber que há um todo uno e homogêneo, sob o ângulo do todo, mas diverso e heterogêneo, sob o aspecto das partes. Esse todo é composto por partes diversas inter-relacionadas". ${ }^{10}$ Não podemos reduzir o todo às partes, muito menos as partes ao todo. São as unidades múltiplas.

Mudou a ficção: em outras palavras, a literatura e a arte que sempre falaram do presbítero mudaram. As narrativas que se repetem não conseguem mais atrair como outrora e, a novidade ainda é obscura. Entretanto, há uma mudança da época presbiteral em andamento cuja formação ainda não despertou para o problema ou acorda tonta e sem rumo na escuridão. Libanio chama nossa atenção para aprender a ser,11 ou seja, sair do extremismo do puro emocional e a desvalorização da razão ou vice-versa. Trata-se de saber ver integralmente a pessoa do presbítero: espírito e corpo. Da conjugação do ser e do ter, da beleza, do ético, da verdade, do bem e da Transcendência.

Então, o modelo presbiteral, a relação com o sagrado, e as narrativas que expressam uma forma de ser no mundo estão se redefinindo. $A$ metamorfose acontece no ver a partir do mito. Daí o surgir de um "novo clero", sobretudo a partir do ano 2000, mesmo que com traços do antigo: mais centralizador, burocrático e com pouca expressão cultural. Como consequência, a conexão está com o avatar que supera em qualidade o real, mas não sobrevive sem este. O papel, portanto, da formação permanente é saber ler o intertexto que aí se produz. Para início de conversa faz-se urgente entender que as leis e os dogmas só poderão ajudar se entendermos suas narrativas, senão serão transgredidos sem nenhum pudor.

9 ELIADE, M. O sagrado e o profano, a essência das religiões. São Paulo: Martins Fontes, 1992, pp. 84-85.

10 LIBANIO, J. B. A arte de formar-se. São Paulo: Loyola, 2001, p. 37.

11 LIBANIO, J. B. As lógicas da cidade, cit., pp. 77ss. 
Quanto mais temos leis, com maior facilidade as transgredimos. Por isso, retornando a Libanio, o saber conhecer e pensar são fundamentais, pois a conexão do conhecimento com o momento presente (sincrônico) e sua formação na história (diacrônico) nos possibilita a organização mental da transversalidade e a articulação do pensar. Por conseguinte, problematizar é preciso. "Triste" - escreve o mesmo Libanio - "é encontrar pessoas [jovens ou adultos] cansadas, abúlicas, obtusas, céticas, desiludidas, que se trancam na impossibilidade de perguntar-se. Vivem dentro da banal certeza de uma vida empobrecida sem curiosidade da mente. A dúvida verdadeira brota de uma inteligência que percebe a complexidade da realidade e da pequenez de suas respostas".12 De forma contundente, surge o empenho de nos ver dentro das obras literárias e da arte, mesmo que elas não falem explicitamente de nós.

\section{NOVO CONTEXTO DA FORMAÇÃO PERMANENTE}

Qual é o contexto da formação inicial-permanente? As narrativas nos dizem que, desde o início da identificação com o modelo presbiteral, o jovem candidato precisa entrar num processo de permanente formação, quer dizer, dentro de um dinamismo que abre horizontes, forma para a vida e gera pessoas significativas. Vale, portanto, o dito de que dentro de cada seminarista tem um padre escondido; assim também, como dentro de cada presbítero existe um bispo em potencial. Assim, ocorre a contínua re-significação da essencialidade do ministério: natureza, identidade e missão, com a dosagem necessária do imaginário social e eclesiástico subjacente. Por isto a Igreja insiste em dizer que "o próprio candidato ao sacerdócio deve ser considerado protagonista necessário e insubstituível de sua formação, autoformação" (PDV, 69)..13

Entretanto, o candidato não está sozinho neste processo. Ele conta com a Igreja, ou seja, o sujeito comunitário que acompanha. Ela é memória e sacramento da ação de Jesus Cristo no meio de nós (PDV 65). Porém, neste corpo eclesial, o bispo é o representante de Cristo na formação dos padres, seja a inicial ou a permanente. Outra realidade formativa é a comunidade educativa do seminário como equipe que acompanha os processos, realiza

\footnotetext{
12 Ibid., p. 24.

13 A sigla PDV, daqui em diante, significa Pastores Dabo Vobis. Conferir bibliografia.
} 
as narrativas e re-significa o imaginário mitológico da identidade presbiteral e do presbítero (PDV 66). Contudo, é imprescindível que o bispo zele pela formação dos formadores.

João Paulo deixou claro na Pastores Dabo Vobis que existe uma razão teológica para a formação permanente, pela força do "dom de Deus recebido" $(2 \operatorname{Tm} 1,6)$. É preciso cuidar de si mesmo para cuidar dos outros, quer dizer "reanimar este dom" a partir da caridade pastoral (PDV 70). Esta caridade é que motiva o presbítero a aprofundar as novas narrativas, a complexidade do mundo e da missão, a ser sensível às esperanças e angústias do povo. Trata-se, pois, de uma "exigência intrínseca ao próprio ministério".

Não é de menos recordar que por este reanimar passa a dimensão humana que nos torna homens mais sensíveis às realidades do cotidiano; é também a dimensão espiritual que nos configura a Cristo; é formação intelectual no aprendizado teológico, pastoral e nas especializações daí decorrentes; também é pastoral, fruto da caridade, dom e tarefa a ser aperfeiçoada no contato com o Povo de Deus (PDV, 72).

A formação permanente nos recorda que somos homens de fé e precisamos crescer sempre mais neste aspecto. Somos, na Igreja, homens de comunhão, partilha e irmão entre irmãos e irmãs. Esta consciência precisa amadurecer segundo nossas idades e vivências para sermos de fato imagens do Cristo Pastor (PDV, 73). Concretamente o padre é o homem da comunhão com o povo, com o presbitério, com o bispo, com os religiosos e as religiosas.

Neste processo de formação, a solidão é um elemento importante da vida do presbítero. João Paulo II escreveu na PDV: "Uma certa solidão é elemento necessário para a formação permanente". Jesus sabia retirar-se, por vezes, para orar sozinho (Mt 14,23). A capacidade de aguentar uma boa solidão é condição indispensável para o cuidado da vida interior. Trata-se de uma solidão habitada pela presença do Senhor, que, na luz do Espírito Santo, nos põe em contato com o Pai. Neste sentido, a procura do silêncio e de espaços e tempos de "deserto" é necessária à formação permanente, seja no campo intelectual, no campo espiritual e no pastoral. Neste sentido ainda, pode-se afirmar: só não é capaz de uma verdadeira e fraterna comunhão quem não sabe viver bem a própria solidão (PDV, 75). 
AS IDADES DA VIDA E VIVÊNCIAS DA FORMAÇÃO PERMANENTE ${ }^{14}$

\begin{tabular}{|c|c|c|c|}
\hline IDADES & $\begin{array}{c}\text { NÍVEIS DE } \\
\text { RESPONSABILIDADES }\end{array}$ & $\begin{array}{l}\text { ACOMPANHAMENTO } \\
\text { FORMATIVO }\end{array}$ & RISCOS \\
\hline $\begin{array}{l}\text { 1a Jovens } \\
\text { padres } \\
+/-27-35 \\
\text { anos }\end{array}$ & $\begin{array}{l}\text { - Internalização do } \\
\text { conhecimento recebido nos } \\
\text { estudos teológicos; } \\
\text { - Assumir a missão presbiteral } \\
\text { no contato direto com o povo: } \\
\text { sonho e cenário; } \\
\text { - Inserção no presbitério e } \\
\text { corresponsabilidade com os } \\
\text { irmãos presbíteros: narrativas; } \\
\text { - Maior criatividade, busca de } \\
\text { fecundidade, iniciativa pastoral } \\
\text { e intelectual. }\end{array}$ & $\begin{array}{l}\text { - Os primeiros cinco anos } \\
\text { devem ser de reflexão } \\
\text { teológico-pastoral-prática } \\
\text { em sintonia com outros; } \\
\text { - Possibilidade de } \\
\text { especialização; } \\
\text { - Cuidado de si: saúde de } \\
\text { corpo, espírito e mente. }\end{array}$ & $\begin{array}{l}\text { - Assumir } \\
\text { cargos de muita } \\
\text { responsabilidade; } \\
\text { - Ter diversas } \\
\text { atividades ao } \\
\text { mesmo tempo; } \\
\text { - Estresse } \\
\text { crônico que gera } \\
\text { incapacidade } \\
\text { diante de novas } \\
\text { responsabilidades. }\end{array}$ \\
\hline $\begin{array}{l}\text { 2a Padres } \\
\text { de meia } \\
\text { idade } \\
+/-35-55 \\
\text { anos }\end{array}$ & $\begin{array}{l}\text { - Assumir cargos de governo } \\
\text { e administração dos conflitos } \\
\text { dos outros; } \\
\text { - Período que começa a } \\
\text { maturidade para guiar outros; } \\
\text { - Melhora a autoestima. }\end{array}$ & $\begin{array}{l}\text { - Avaliar a capacidade de } \\
\text { escuta, de trabalho em } \\
\text { equipe; } \\
\text { - Favorecer encontros que } \\
\text { fortaleçam a consciência } \\
\text { do ser presbítero; } \\
\text { - Participar de cursos } \\
\text { de atualização bíblica, } \\
\text { teológica e pastoral, } \\
\text { semanas de estudos, } \\
\text { conferências; } \\
\text { - Possibilidade de } \\
\text { acompanhamento } \\
\text { psicológico e pedagógico } \\
\text { em vista da missão; } \\
\text { - Formação em técnicas } \\
\text { de comunicação; } \\
\text { - Cuidado de si: corpo e } \\
\text { mente. }\end{array}$ & $\begin{array}{l}\text { - Concentração } \\
\text { de poder: } \\
\text { autoritarismo, } \\
\text { clericalismo; } \\
\text { - Crise do lobo } \\
\text { - diabo do } \\
\text { meridiano - o } \\
\text { que fiz? Quais } \\
\text { resultados? } \\
\text { - Perder o } \\
\text { entusiasmo inicial; } \\
\text { - A busca da } \\
\text { eficiência ofusca a } \\
\text { eficácia. }\end{array}$ \\
\hline
\end{tabular}

14 Para elaborar esta tabela, contei com a indicação dos seguintes autores e suas respectivas obras: João Paulo II, Pastores Dabo Vobis, nn. 77-80; João da Silva Mendonça Filho, As idades da vida na vida religiosa, vivência humana e espiritual. São Paulo: Paulinas, 2002, pp. 38-67; Agostino Favale, I presbiteri, identità, missione, spiritualità e formazione permanente. Torino: ElleDiCi, 1999, pp. 348-360. 


\begin{tabular}{|c|c|c|c|}
\hline $\begin{array}{l}\text { 3a Padres } \\
\text { da idade } \\
\text { madura } \\
+/-55-75 \\
\text { anos }\end{array}$ & $\begin{array}{l}\text { - Os estudos devem ajudar na } \\
\text { coerência de vida e na paixão } \\
\text { pela missão; } \\
\text { - Ter possibilidade de } \\
\text { apostolado e exercício de } \\
\text { sua competência pastoral no } \\
\text { encontro com as pessoas e } \\
\text { testemunho da caridade; } \\
\text { - Manter a mente aberta para } \\
\text { o novo. }\end{array}$ & $\begin{array}{l}\text { - Possibilidade de contato } \\
\text { com as novas gerações } \\
\text { de presbíteros; } \\
\text { - Manter ritmo de leitura; } \\
\text { - Melhorar o nível de } \\
\text { empenho apostólico e } \\
\text { espiritual; } \\
\text { - Aprender a envelhecer } \\
\text { serenamente; } \\
\text { - Cuidado de si: mente. }\end{array}$ & $\begin{array}{l}\text { - Ser deixado à } \\
\text { margem da vida } \\
\text { eclesial; } \\
\text { - Sentir-se } \\
\text { superado. }\end{array}$ \\
\hline $\begin{array}{l}\text { 4a Padres } \\
\text { em idade } \\
\text { avançada } \\
+/-75 \\
\text { anos }\end{array}$ & $\begin{array}{l}\text { - Receber estímulos para } \\
\text { colaborar com novas frentes } \\
\text { de apostolado segundo a } \\
\text { saúde; } \\
\text { - Contato com as novas } \\
\text { gerações de presbíteros; } \\
\text { - Reduzir atividades externas } \\
\text { e dedicação à pastoral do } \\
\text { acompanhamento. }\end{array}$ & $\begin{array}{l}\text { - Ser sustentado na } \\
\text { alegria do dom recebido: } \\
\text { "Completo na minha } \\
\text { carne o que falta aos } \\
\text { sofrimentos de Cristo, em } \\
\text { favor do seu Corpo, que é } \\
\text { a Igreja" (Cl 1,24); } \\
\text { - Cuidado de si: saber } \\
\text { aceitar a debilidade } \\
\text { física e o cansaço com } \\
\text { naturalidade; } \\
\text { - Aceitar a morte como } \\
\text { fidelidade ao dom } \\
\text { recebido: união plena com } \\
\text { Deus. }\end{array}$ & $\begin{array}{l}\text { - Evitar o } \\
\text { isolamento da } \\
\text { comunidade } \\
\text { eclesial e do } \\
\text { presbitério. }\end{array}$ \\
\hline
\end{tabular}

\section{CONCLUSÃO: PERSPECTIVAS PARA O MINISTÉRIO NESTA METAMORFOSE ${ }^{15}$}

Para concluir essas reflexões, apresento em forma sintética os valores que acredito serem importantes para o padre de hoje e de amanhã como testemunho de fé, esperança e caridade:

1. Vivência genuína da fé partilhada: a fé é um dom recebido que se aprofunda à medida que sabemos partilhar. $O$ padre não pode esquecer que precisa aprender a partilhar a fé recebida. Nada é tão forte na vida de um cristão quanto a gratidão. Deus é gratuidade: ao nos presentear com a fé, somos gratidão na partilha.

15 O texto completo pode ser encontrado em: VALLE, E. Padre, você é feliz?, cit., pp. 138-139. 
2. Abertura às pessoas, aos jovens e ao mundo: a capacidade de se relacionar com todos, sobretudo com os mais frágeis, são fundamentais para o padre. Num mundo marcado pela velocidade, às vezes perdemos a dimensão do outro, da importância que o outro exerce em nossas vidas. O padre deve estar atento para não perder este dinamismo importante: ser homem de relações profundas com todos, sobretudo com os jovens. O mundo, assim, se abre ao padre com toda a sua energia, e o padre se abre ao mundo para transformá-lo.

3. Viver a riqueza das relações fraternas com todos: ser pessoa de relações fraternas, de laços de comunhão e solidariedade; eis um dos empenhos do padre de hoje e de amanhã. É fácil romper laços, criar divisões e alimentar o ódio. O padre é o homem da comunhão. A partir da Eucaristia ele se torna o que celebra: doação aos outros, assim como Cristo. Portanto, ser capaz de manter relações profundas é uma missão fundamental do padre.

4. Seguir Jesus Cristo na gratuidade do dom recebido: a vocação é um dom que o padre recebe pela pura gratuidade de Deus que chama. Nós não escolhemos seguir a Deus no ministério presbiteral; é Ele quem nos escolhe e atrai a partir dos fatos, das pessoas e da sua Palavra. Portanto, nossa vocação é pura gratidão. Trata-se de uma vida que se doa a cada dia para que o mundo creia. $\mathrm{O}$ padre é um discípulo missionário que faz caminhos em comunhão com o povo. O ministro de hoje e de amanhã será feliz à medida que souber doar a vida para que outros tenham vida em abundância.

5. Não seja um funcionário de Deus, mas servidor de Deus: às vezes temos a impressão de que alguns padres perdem o entusiasmo inicial. Perdem as razões daquele primeiro amor e se tornam meros funcionários do poder entregues aos trabalhos burocráticos, a um clericalismo selvagem, ao distanciamento do povo. Por isso, é importante dizer que o padre de hoje e de amanhã precisa recuperar a paixão por Deus, ao qual serve, e ao povo ao qual se doa sem medidas.

6. Paciência histórica para semear, regar, adubar, cuidar e colher resultados: Deus é paciente conosco. O padre, a exemplo do amor compassivo de Deus, deve ser homem paciente, sobretudo com os mais pobres. Esperar contra toda esperança, semear onde ninguém acredita que é possível gerar vida, erguer os caídos, curar os doentes, libertar os presos. Para tanto, o padre precisa ter paciência e credibilidade no ser humano. 


\section{REFERÊNCIAS BIBLIOGRÁFICAS}

FAVALE, A. I presbiteri, identità, missione, spiritualità e formazione permanente. Torino: ElleDiCi, 1999.

JOÃO PAULO II. Exortação Apostólica pós-sinodal Pastores Dabo Vobis, sobre a formação dos sacerdotes. São Paulo: Paulinas, 1992.

LIBANIO, J. B. As lógicas da cidade, o impacto sobre a fé e sob o impacto da fé. São Paulo: Loyola, 2001. . A arte de formar-se. São Paulo: Loyola, 2001.

MIRCEA, E. O sagrado e o profano - a essência das religiões. São Paulo: Martins Fontes, 1992.

RUSSO, G. C. Essere sacerdote in un mondo che cambia. Milano: Italya, 1994.

SANTOS, J. B. O presbítero Católico - uma identidade em transformação. Aparecida: Santuário, 2010.

SILVA, J. M. F. As idades da vida na vida religiosa, vivência humana e espiritual. São Paulo: Paulinas, 2002.

SUES, P. Memória, discernimento, compromisso: comunhão e missão presbiteral ontem e hoje. Palestra proferida no 13o. ENPs (3-4/02/2010) Itaici/SP.

VALLE, E.; BENEDETTI, L. R. (org.). Padre, você é feliz? Uma sondagem psicossocial sobre a realização pessoal dos presbíteros no Brasil. São Paulo: Loyola, 2004.

ZEZINHO, Pe. Por uma Igreja que pensa. In: Jornal O Lutador. Junho-julho/2010. 